\title{
Malakoplakia in a colonic tubular adenoma: a unique case presentation
}

\author{
Akash Gupta1 , Abdalla Saad Abdalla Al-Zawi' ${ }^{2}$ Asghar Naqvi ${ }^{3}$, Samih Salama ${ }^{3}$, \\ Emraga Abohamod ${ }^{4}$, Salem Alowami ${ }^{3}$
}

Malakoplakia is an unusual characteristic inflammatory condition, it is distinctive feature is the presence of histiocytic cells with eosinophilic granular cytoplasm, often known as "von Hansemann's histiocytes", along with the pathognomonic siderocalcific Michaelis-Gutmann bodies (MGBs). We present a case of malakoplakia within a colonic adenoma seen against a background of Enterococcus infection. To our knowledge, this is a unique presentation which has not previous been described.

NOWOTWORY J Oncol 2017; 67, 6: 365-369

Key words: malakoplakia, colonic adenoma, Enterococcus, Michaelis-Gutmann bodies

\section{Introduction}

Malakoplakia is a chronic inflammatory response of uncertain aetiology. The German Professor von Hansemann saw the first human case in 1901 [1], where most of the literature records report that, his assistant Dr Michaelis and the biochemist Gutmann were the first who described the malakoplakia in 1902 [2,3]. This condition is thought to be due to defective histiocytic function. The histiocytes have enlarged phagosomes containing non-digested bacteria along with cytoplasmic mineralized basophilic concretions with a targetoid appearance, surrounded by a simple lysosomic-type membrane and there are termed Michaelis-Gutmann bodies (MGBs) [4,5]. This reaction is most commonly seen in the urinary bladder [6], but has also been reported in the gastrointestinal system [7, 8], skin [9] and vagina [10]. Incidental findings of malakoplakia in the gastrointestinal tract have been shown to have an association with colorectal carcinoma [11]. We present a case of malakoplakia within a colonic adenoma seen against a background of Enterococcus infection. To our knowledge, this is a unique presentation which has not previous been described.

\section{Case description}

A 67 year old female presented to the Emergency Unit with a 3 month history of nausea, vomiting, and diarrhea after a recent trip to Mexico. She was given a two-week course of oral Metronidazole for treatment of an initial diagnosis of Clostridium difficile infection.

Two days after finishing the antibiotics, she developed acute right lower quadrant abdominal pain with emesis. She returned back to the hospital where she was found to be hypotensive with tachycardia. She was transferred to a tertiary care hospital ICU (Intensive Care Unit) for management of her MOF (Multiple Organ Failure) including septic shock and DIC (Disseminated Intravascular Coagulopathy). She had a complex management course requiring intensive medical support as intubation, ventilation, vasopressors and continuous renal dialysis. Blood cultures were found to be positive for Enterococcus faecium and she has been treated with Vancomycin, in addition to initial broad spectrum antibiotics. Throughout her stay in the hospital, the patient was quite anemic, and a colonoscopy was performed to assess for any possible Gl source of bleeding. The colonoscopy revealed moderate diffuse diverticula as well as

\footnotetext{
${ }^{1}$ Department of Pathology and Molecular Medicine, McMaster University, Hamilton, Ontario, Canada ${ }^{2}$ Department of Surgery, Basildon and Thurrock University Hospital, Essex, United Kingdom ${ }^{3}$ Department of Pathology and Molecular Medicine, St. Joseph's Healthcare, Hamilton, Ontario, Canada ${ }^{4}$ Department of Anatomy, Sebha University Medical School, Libya
} 


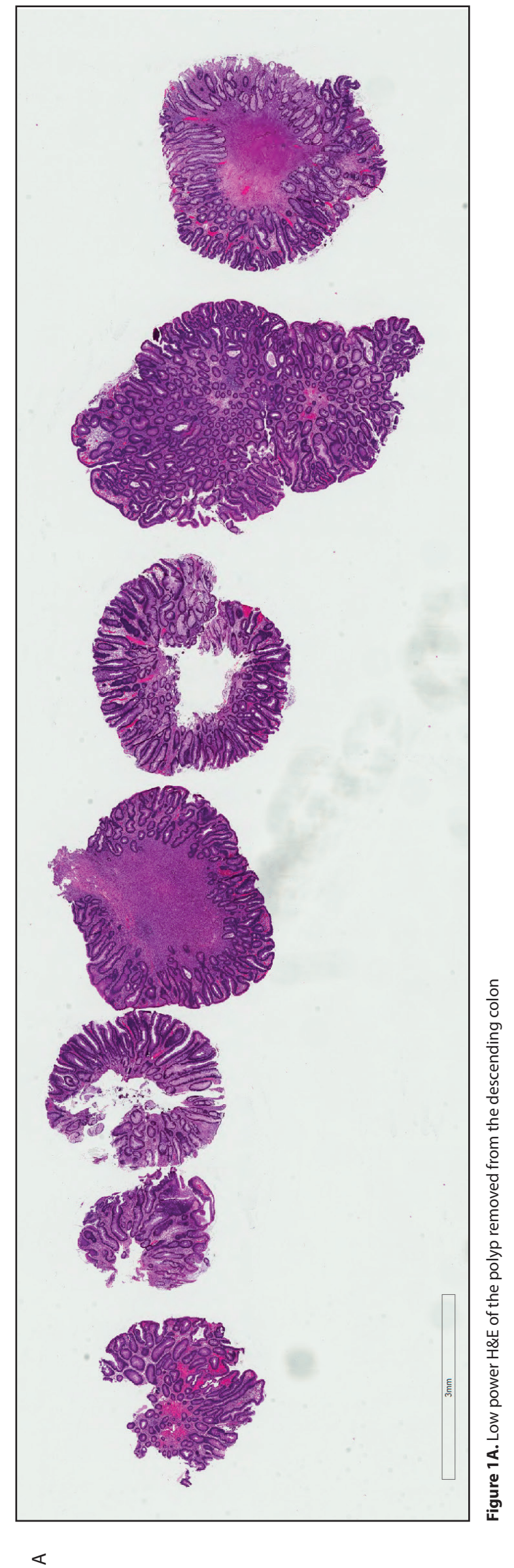


B

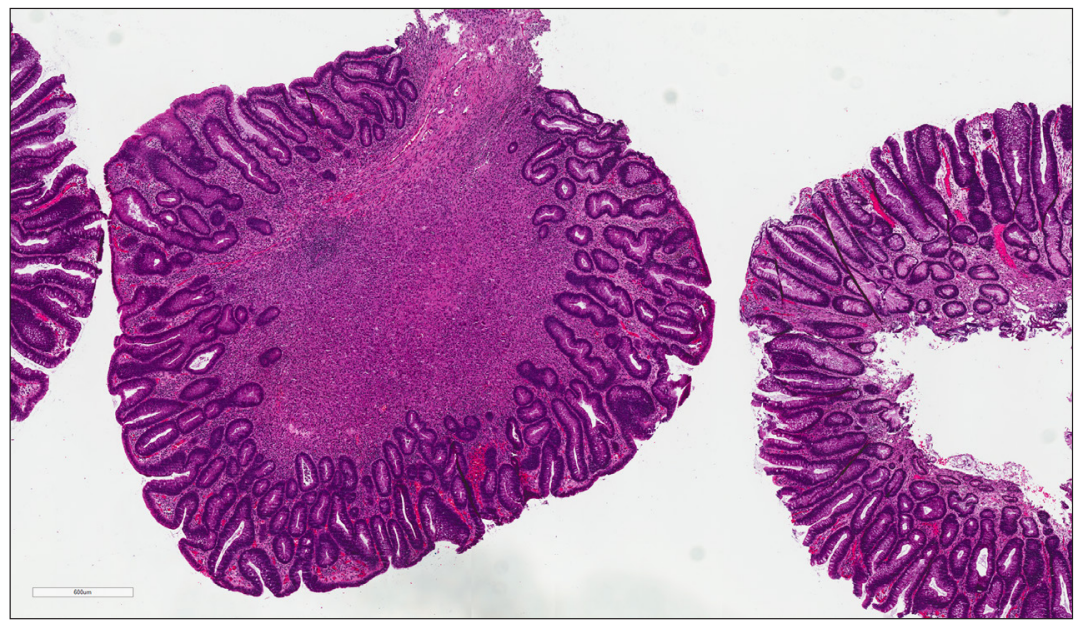

C

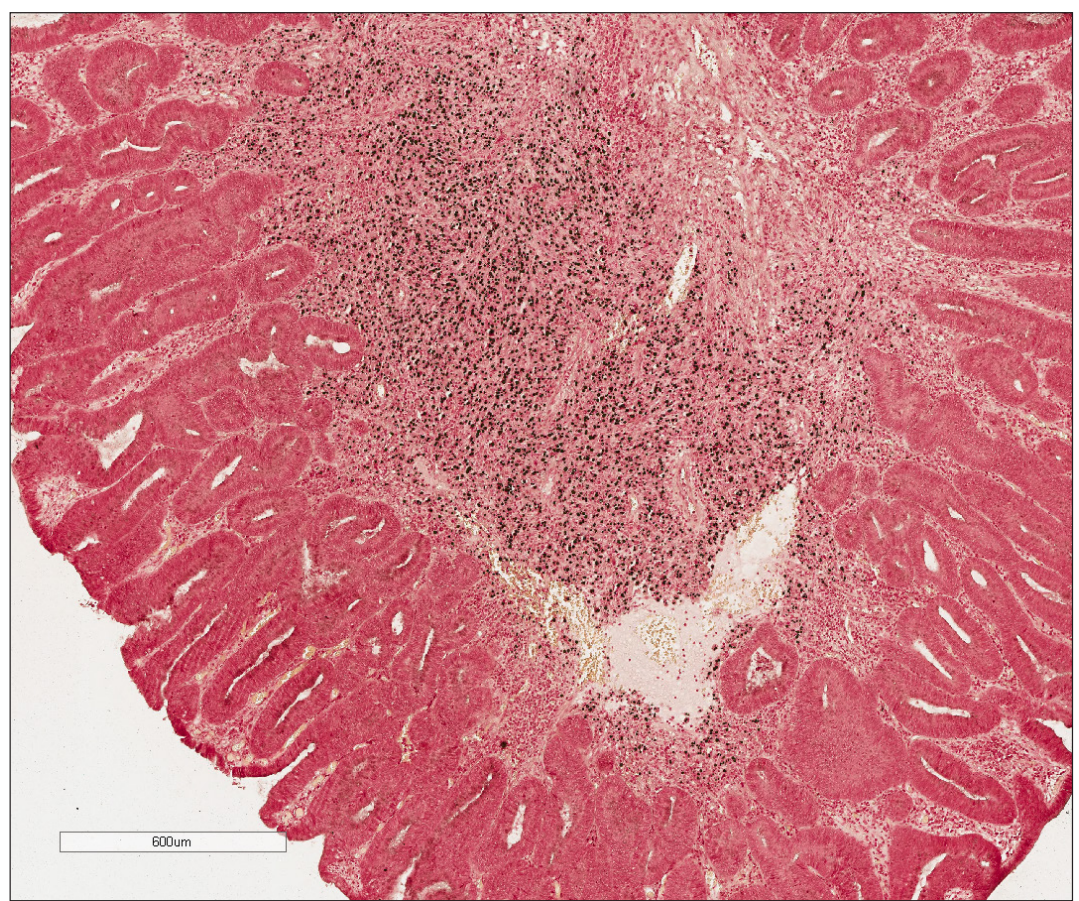

D

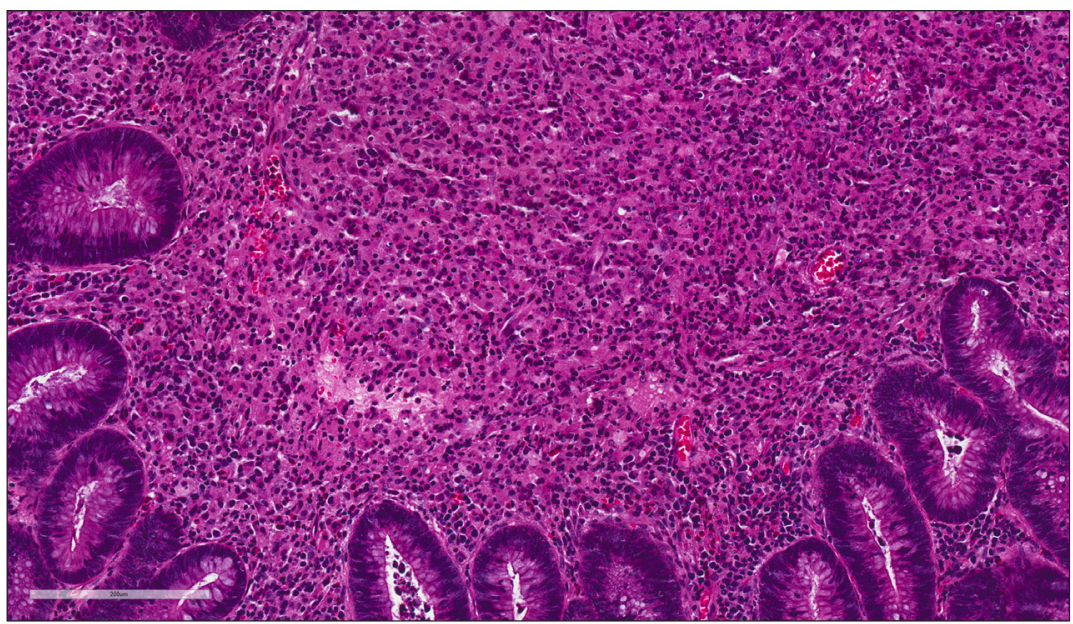

Figure 1. B. High power magnification of the tubular adenoma. C. Very high power magnification demonstrating the inflammatory infiltrate composed of histiocytes. D. Von Kossa stain highlighting the presence of calcium and Michaelis-Gutmann bodies 
four colonic polyps, which were removed at that time. The sections of the polyp removed from the descending colon showed features consistent with a tubular adenoma with no evidence of high grade dysplasia. The lamina propria was greatly expanded due to the increased presence of numerous foamy epithelioid histiocytes and a small focus of lymphocytes. The histiocytes contained elements of non-digested bacteria, which stained positive with a Von Kossa special stain. The microscopic features and staining pattern were confirmatory for a diagnosis of malakoplakia (Figure 1: A-D).

\section{Discussion}

Malakoplakia is an uncommon, but distinct, inflammatory process of uncertain aetiology. Most of the text books reported that, first was described in 1902 by Michaelis and Gutmann [2], however the reports mentioned that Professor von Hansemann saw the first human case of malacoplakia on 14 May 1901 [1]. This is why some papers calling this disease as von Hansemann's disease. The word malacoplakia was suggested by Professor von Hansemann himself, and it was derived from Greek words malakos (soft) and plakos (plaque) [3]. The mode of the occurrence in relation to age is characterised by bimodal pattern, the first prevalence is below age of 13 and the second group is the middle-aged adults, however the average age at diagnosis is 50 years [12-18]. It has since been reported at other sites, including the gastrointestinal tract (GIT) [7, 8, 19], the skin [9], the vagina [10], the central nervous system [20], the lungs [21], pancreas [15] and the gallbladder [22].The second group is the middle-aged adults, however the average age at diagnosis is 50 years [12-14]. Clinical presentation varies from incidental finding during a procedure, to a symptomatic mass lesion. It has been commonly reported in cases invoIving the genitourinary tract (70\%) [15], and most often in the urinary bladder [16], and it has been mistaken for malignancy [17]. Malakoplakia was first reported outside of the genitourinary system in 1958 by Haukohl and Chinchinian [23]. Regarding the GIT involvement, it has been regarded as the second most common site (12-15\%) [14], and frequently seen in the left hemi-colon, between the descending colon and rectum $[19,24]$.The pathogenesis of malakoplakia is not completely understood, but three possible mechanisms have been suggested [16]. These mechanisms suggest that malakoplakia may be due to specific microorganisms, from which Escherichia coli, Mycobacterium tuberculosis, Proteus, and Staphylococcus aureus are the most likely agents, an abnormal or altered immune response in the patient, or due to defective lysosomal function In immunocompromised patients, chronic infection may result in lowering levels of cyclic guanosine monophosphate nucleotide (cGMP) in the cellular microtubules. This nucleotide acts as a second messenger much like cyclic AMP (adenosine monopho- sphate), and it plays part in activation of intracellular protein kinases. The protein kinases are the enzymes which are helpful in phosphorylation of many proteins, among, them the immunoglobulins and lytic enzymes $[14,15]$. The macrophages are still able to engulf the bacteria, however unable to destroy them. The outcome will be the presence of intracellular inclusion bodies, formed of undigested bacterial bodies, glycolipid, iron and calcium deposits, giving the appearance of Michaelis-Gutmann bodies (MGBs). These inclusion bodies usually stain positive with Von-Kossa and Prussian Blue stains. The association of the malakoplakia and the immunological conditions as immunodeficiency or immunosuppression as in transplantation has been reported $[14,15]$. Malakoplakia found within the genitourinary tract is most often associated with an Escherichia coli infection. It has been proposed that development of malakoplakia within the gastrointestinal tract could be due to the same organism as well, likely secondary to superficial mucosal ulceration. Our patient is an immunocompetent host with a blood culture positive Enterococcus faecium septicemia. Although her initial presentation resembled that of a Clostridium difficile infection, her colonoscopy showed no evidence of pseudo-membranes or inflammation. Previously reported cases of incidental malakoplakia found within colonic adenomas have reported an association with colorectal carcinoma [7], however our histological examination revealed no evidence of high grade dysplasia. Given her three month history of feeling unwell, it is possible that an underlying Enterococcus faecium infection could be the causative factor for development of malakoplakia within a colonic adenoma in this case.

\section{Conclusion}

Although often found in the genitourinary tract, malakoplakia has been reported in many other systems. With regards to the gastrointestinal tract, there has been an association with the presence of colorectal carcinoma. Pathologists should be aware that these lesions can exist and that there are several possibilities with regards to etiology.

Conflict of interest: none declared

\author{
Akash Gupta, MD, PhD \\ McMaster University \\ Department of Pathology and Molecular Medicine \\ 1280 Main Street West, HSC-2N16 Hamilton, L8S 4K1, Canada \\ e-mail:akash.gupta@medportal.ca
}

Received: 28 Dec 2017

Accepted: 13 Feb 2018

This case report has been presented as an e-poster at the Canadian Association of Pathology annual meeting in Vancouver, Canada, Jul 2016 


\section{References}

1. Von Hansemann D. Über Malakoplakie der Harnblase. Virch Arch Path Anat 1903; 173: 302-308.

2. Michaelis L, Gutmann C. Einschlüsse in Blasentumoren. Z Klin Med 1902; 47: 208-215.

3. Dasgupta P, Womack C, Turner A et al. Malacoplakia: Von Hansemann's disease. BJU Int 1999; 84: 464-469.

4. Ghadially FN. Ultrastructural pathology of the cell and matrix. 4th ed. Vol 2. Boston: Butterworth-Heinemann, 1997: 720-723.

5. Damjanov I, Katz SM. Malakoplakia. Pathol Annu 1981;16(Pt 2): 103-126.

6. Ben Amna M, Hajri M, Oumaya C et al. Genito-urinary malacoplakia. Report of 10 cases and review of the literature [in French]. Ann Urol (Paris) 2002; 36: 388-391.

7. Asiyanbola B, Camuto P, Mansourian V. Malakoplakia occurring in association with colon carcionma. J Gastrointest Surg 2006; 10:657-661.

8. Rizzo E, Sandmeier D, Hack I et al. Malakoplakia and colonic adenoma: a rare association. Ann Diagn Pathol 2004; 8: 364-366.

9. Barnard M, Chalvardjian A. Cutaneous malakoplakia in a patient with acquired immunodeficiency syndrome (AIDS). Am J Dermatopathol 1998; 20: 85-88.

10. Van der Walt JJ, Marcus PB, DeWet JJ et al. Malacoplakia of the vagina. First case report. S Afr Med J 1973; 47: 1342-1344.

11. Pillay K, Chetty R. Malakoplakia in association with colorectal carcinoma: a series of four cases. Pathology 2002; 34: 332-335.

12. Pozo Mengual B, Burgos Revilla FJ, Briones Mardones G et al. Malacoplaquia vesical con afectación ganglionar y curso agresivo. Actas Urol Esp 2003; 27: 159-163.

13. Patnayak R, Reddy MK, Subramanian $S$ et al. An unusual case of bilateral hydroureteronephrosis caused by uretero-vesico malakoplakia in a young male: a case report and review of the literature. Cases J 2009; 2: 7527.

14. Madruga M, Nagel J, Milito CB et al. Pulmonary malakoplakia associated with immunodeficiency by HTLV-1 and HIV. J Bras Patol Med Lab 2014; 50: 296-299.

15. Guha S, Liu H. Malakoplakia of the pancreas with simultaneous colon involvement: Case report and review of the literature. Case Rep Pathol 2015; 2015: 649136.

16. Yousef GM, Naghibi B, Hamodat MM. Malakoplakia outside the urinary tract. Arch Pathol Lab Med 2007; 131: 297-300.

17. Heah NH, Tan TW, Tan YK. Malakoplakia of the prostate as a mimicker of prostate cancer on Prostate Health Index and magnetic resonance imaging-fusion prostate biopsy: a case report. J Endourol Case Rep 2017; 3: 74-77.

18. Scott EV, Scott WF Jr. A fatal case of malakoplakia of the urinary tract. JUrol 1958; 79: 52-56.

19. Gargade CB, Desai AY. Colonic adenocarcinoma with malakoplakia of colon: A case report. J Evolution Med Dent Sci 2015; 4: 12955-12959.

20. Rickert $\mathrm{CH}$, August $\mathrm{C}$, Brandt $\mathrm{M}$ et al. Cerebral malakoplakia associated with Escherichia coli infection. Acta Neuropathol 2000; 99: 595-598.

21. Shin MS, Cooper JA Jr, Ho KJ. Pulmonary malacoplakia associated with Rhodococcus equi infection in a patient with AIDS. Chest 1999; 115:889-892.

22. Rathod SS, Dahiya D, Talukder $S$ et al. Malakoplakia of gallbladder: A histological surprise. Gastroenterol Pancreatol Liver Disord 2017:4:1-3.

23. Finlay-Jones LR, Blackwell JB, Papadimitriou JM. Malakoplakia of the colon. Am J Clin Pathol 1968; 50: 320-329.

24. Alavian SM, Raissi SF, Kamalian N. Malakoplakia of the colon: A case report and literature review. MJIRI 2001; 15:179-182. 